\title{
Artificial Intelligence Design of Public Transportation
}

\author{
Xiaolu WANG \\ Jinan University, College of civil engineering and \\ architecture \\ The faculty of architecture \\ Jinan city, China \\ cea_wangxl@ujn.edu.cn
}

\author{
Yading SUN \\ Tongyuan Architectural Design Group Co.Ltd \\ The first department of architecture design \\ Jinan City, China \\ 2651379188@qq.com
}

\begin{abstract}
This paper mainly focus on the optimization of Jinan city. In order to improve the public transportation issues of Jinan, we have designed a more intelligent, greener transportation than ever before, including the public transportation facilities and public transportation data sharing systems. In the aspect of public transportation facilities, the use of solar panels have been joined as the roof of the bus station and the humanized facilities also have been joined into the design. In addition, we have designed the shape of the bus station newly. In terms of the public transportation data sharing systems, we have a thought that it is essential to develop a mobile application which could acquire the real-time information of the public transportation and get use of the cameras in bus to transmit the real-time video to the screen of the bus station's platform, which can provide the information such as the degree of crowdedness in the bus for the people who is waiting for the bus. This design will provide people with more traffic information and make people more efficient and convenient, which can carry out the sustainable strategy of the city.
\end{abstract}

Keywords-public transportation system; artificial intelligence; green energy; city portal image; public transportation; data sharing

\section{THE APPLICATION OF GREEN ENERGY}

\section{A. LED energy saving lamp lighting system}

LED (light emitting diode) is a light-emitting diode, a kind of solid state semiconductor device capable of converting electric energy into visible light. LED energy-saving lamp is high efficiency and energy saving, long life, environmental protection, high light efficiency and high safety coefficient; at the same time, the light control and time control could be more flexible to control and suitable for various public places lighting for a long time. As it shown in table I:

TABLE I. COMPARISON OF COMMON LAMP PERFORMANCE

\begin{tabular}{|c|c|c|c|c|c|}
\hline Types & $\begin{array}{c}\text { Lighting } \\
\text { efficiency/(1 } \\
\mathbf{m} / \mathbf{W})\end{array}$ & $\begin{array}{c}\text { Average } \\
\text { life/h }\end{array}$ & \multicolumn{2}{|c|}{$\begin{array}{c}\text { The mode of } \\
\text { power supply }\end{array}$} & \multicolumn{2}{|c|}{$\begin{array}{c}\text { Time consuming } \\
\text { of } \mathbf{1} \text { kwh under } \\
\text { the same } \\
\text { brightness/h }\end{array}$} \\
\hline $\begin{array}{c}\text { Incandescent } \\
\text { lamp }\end{array}$ & 15 & 1000 & $\begin{array}{c}\text { Alternating } \\
\text { current }\end{array}$ & $60 \mathrm{~W}$ & 17 \\
\hline $\begin{array}{c}\text { Ordinary } \\
\text { energy-saving } \\
\text { lamps }\end{array}$ & 55 & 8000 & $\begin{array}{c}\text { Alternating } \\
\text { exchange }\end{array}$ & $5 \mathrm{~W}$ & 200 \\
\hline $\begin{array}{c}\text { LED energy } \\
\text { saving lamp }\end{array}$ & 60 & 50000 & $\begin{array}{c}\text { Low voltage } \\
\text { direct current }\end{array}$ & $3 \mathrm{~W}$ & 333 \\
\hline
\end{tabular}

a. Comparison of common lamp performance

\section{B. Confirm the best optimum inclination of solar panels}

In the design of photovoltaic power generation system, whether the dip angle is right or not directly affects the performance and power generation of photovoltaic system. Therefore, in the design of bus station roof, to confirm the best optimum tilt angle must be based on local latitude, making solar radiation ceiling on the plane meets the needs of continuity, uniformity and maximality to reduce the cost of the system. The monthly average solar radiation in Jinan is shown in table II:

TABLE II. AVERAGE SOLAR RADIATION PER MONTH IN JINAN

\begin{tabular}{|c|c|c|c|c|}
\hline Coefficient Month & A & B & R & F \\
\hline 1 & 0.081 & 1.029 & 0.834 & 84.7 \\
\hline 2 & 0.128 & 0.953 & 0.849 & 95.3 \\
\hline 3 & 0.050 & 1.150 & 0.802 & 66.8 \\
\hline 4 & 0.058 & 1.211 & 0.811 & 71.3 \\
\hline 5 & 0.124 & 1.103 & 0.824 & 78.2 \\
\hline 6 & 0.043 & 1.297 & 0.831 & 82.4 \\
\hline 7 & -0.046 & 1.494 & 0.760 & 50.5 \\
\hline 8 & 0.062 & 1.230 & 0.705 & 36.6 \\
\hline 9 & 0.062 & 1.220 & 0.798 & 64.7 \\
\hline 10 & 0.002 & 1.325 & 0.884 & 132.1 \\
\hline 11 & -0.049 & 1.393 & 0.918 & 199.5 \\
\hline 12 & 0.086 & 1.079 & 0.856 & 101.1 \\
\hline b. average solar radiation per month in Jinan (According to Jinan Meteorological Bureau 2013)
\end{tabular}

For the calculation of the inclined plane of solar irradiance, we could use sky radiation model of sky scattering radiation anisotropy proposed by Hay10 to calculate the solar radiation in equatorial different angle received on the array surface. The expression is:

$\mathrm{H}_{\mathrm{T}}=\mathrm{H}_{\mathrm{B}} \mathrm{R}_{\mathrm{B}}+\mathrm{H}_{\mathrm{D}}\left[\mathrm{R}_{\mathrm{B}} \mathrm{H}_{\mathrm{B}} / \mathrm{H}_{0}+0.5\left(1-\mathrm{H}_{\mathrm{B}} / \mathrm{H}_{0}\right)(1+\cos \beta)\right]+0.5 \rho \mathrm{H}(1-\cos \beta)$ $\mathrm{R}_{\mathrm{B}}=\cos \theta_{\mathrm{i}} / \cos \theta_{\mathrm{z}}$

The formula of hour angle of sunrise and sunset:

$\omega_{\mathrm{s}}=\cos ^{-1}[-\tan \Phi \tan \delta](1)$

The angle of incidence: $\theta_{\mathrm{i}}=\cos ^{-1}\left[\cos \theta_{\mathrm{z}} \cos \beta+\sin \theta_{\mathrm{z}} \sin \beta \cos \left(\gamma_{\mathrm{s}^{-}}\right.\right.$ $\gamma)](2)$ 
Zenith angle: $\theta_{\mathrm{z}}=\cos ^{-1}[\sin \delta \sin \Phi+\cos \delta \cos \Phi \cos \omega](3)$

Solar azimuth: $\gamma_{\mathrm{S}}=\sigma_{\mathrm{ew}} * \sigma_{\mathrm{ns}}{ }^{*} \gamma_{\mathrm{so}}+\left[1-\sigma_{\mathrm{ew}} * \sigma_{\mathrm{ns}} / 2\right]^{*} \sigma_{\omega} * 180^{\circ}(4)$

$\gamma_{\text {so }}=\sin ^{-1}\left[\sin \omega \cos \delta / \sin \theta_{2}\right]$,

$\sigma_{\mathrm{ew}}=\left\{1,|\omega| \leq \omega_{\mathrm{ew}}-1\right.$,others $\}$

$\sigma_{\mathrm{ns}}=\{1,(-\delta) \geq 0-1$, others $\}$

$\sigma_{\omega}=\{1, \omega \geq 0-1$,others $\}$

$\omega_{\mathrm{ew}}=\arccos (\tan \delta \tan \Phi)$

( $\Phi$-latitude; $\delta$-declination; $\beta$ - inclined angle, $\rho$ Surface reflectivity, $\theta \mathrm{i}$ — The angle of incidence, $\theta \mathrm{z}$ - solar Zenith angle; $\alpha$-Solar elevation angle; $\gamma$-Surface azimuth, $\gamma$-Solar azimuth)

Through the calculation of the Hay model, we could see that the monthly average solar irradiance changes of different inclination angles in Figure 3.It shows that the annual trend of solar radiation in Jinan is largest in May and smallest in December. Although in July the total radiation is largest, because June and July are in flood season, with more rainy days, less sunshine and under the effect of the days, radiation intensity is being influenced. And summer wind prevails in May, with more fine weather; the total radiation at that time is next to that of in June and July. Therefore, the total radiation of solar is maximum in May. In December Jinan is in winter, whose total radiation and actual total radiation are at the lowest point.

Integrated several aspects of the factors, the $28^{\circ}$ layout tilt angle of solar cell module in Jinan is defined from the local latitude $36.36^{\circ}$, which could not only properly take care the increase of electricity load in winter, and the give the best output in the spring, produce relatively more power after the summer could, quickly recovery charge for battery and prolong the life of battery.

\section{The confirmation of the capacity of solar panels and batteries}

Confirming the combination of solar cell and battery capacity is under the premise of ensuring the reliability of LED lighting load, determining the minimal use of solar battery module and battery capacity optimization design to achieve the best combination of reliability and economy. For reliability, both at home and abroad mostly use the electric load rate (LOLP) to measure, which is defined as the system and the actual needs of the electrical power outage time ratio. When the LOLP value is between 0 and 1 , the value is smaller, and the reliability is higher. Therefore in the design of solar street lamp, while meeting the reliability of load, we need to have the best economy. Learning from the photovoltaic module LOLP recommended value; we can know that the Jinan bus station design of solar lighting system reliability of the LOLP value is 0.1 , which could guarantee the power supply for 4-5 rainy days (the special case is compensated by city electricity). According to this reliability design, the system configuration is shown as table III:
TABLE III. THE COMPONENT OF SOLAR PHOTOVOLTAIC SYSTEM

\begin{tabular}{|c|c|c|}
\hline Component & Number & Parameter \\
\hline Solar cell module & 2 & $\begin{array}{c}\text { Pmp }=20 \mathrm{~W}, \mathrm{Vmp}=18.0 \mathrm{~V}, \operatorname{Imp}=1.11 \mathrm{~A}, \\
\text { Voc }=21.8 \mathrm{~V}, \text { Isc }=1.30 \mathrm{~A}\end{array}$ \\
\hline Storage battery & 1 & $\begin{array}{c}12 \mathrm{~V}, 40 \mathrm{AH} \\
\text { Maintenance free lead-acid battery }\end{array}$ \\
\hline Lighting device & 1 & 8 high power white lights LED \\
\hline Solar controller & 1 & $\begin{array}{l}\text { Light control, anti-battery discharge, } \\
\text { charging function }\end{array}$ \\
\hline
\end{tabular}

c. the component of solar photovoltaic system (Note: the above one is only a simple example, and the detailed parameters need to be tested.)

\section{CITY PORTAL IMAGE AND HUMANIZED DESIGN OF BUS STATION}

According to the Urban Bus Station Design Code, the magnitude of the first and the last the station is determined by the total number of vehicles equipped with the route. General number of vehicle allocation (converted to standard cars) greater than 50 is considered as large station; 26-50 vehicles is medium-sized station; equal to or less than 25 is small station. The first and last stations are usually near residential and commercial areas, which are at a certain space, rich road area and concentrated population, making the general passengers are in the range of $350 \mathrm{~m}$ radius with the station as the center, and the farthest passengers should be at the $700-800 \mathrm{~m}$ radius. General bus station only have waiting corridor, the length of which should be no more than 1.5-2.0 time of the standard length, and full width should be no less than $1.2 \mathrm{~m}$. When we set midway station on the street with small passenger flow, the waiting gallery could be properly reduced, and the corridor length should be no less than $5 \mathrm{~m}$. When setting staging station on the road which roadway width is below $10 \mathrm{~m}$,it should be built to avoid lane, that is the sidewalk in an isosceles trapezoid shape concave set along the margin of no less than $2.5 \mathrm{~m}$, and the concave opening length should be less than $22 \mathrm{~m}$. At present, the bus station Jinan city has the problems of insulating hot and cold, blocking rain, covering the sun, narrow space, accommodating not too many people, and lacking humanized function. In view of the current situation, this research group intends to transform the design of bus station.

\section{A. Ceiling renovation design:}

Change the ceiling into a bar type solar roof. The ceiling comprises a fixed plate and the movable plate, the fixed plate is a double-layer structure, the movable plate in the middle, photovoltaic panels are installed on the outer surface and the movable plate, and movable plate could overlap or extend the fixed plate under the drive of actuating system to change the cover area of the roof and light receiving area. So, when the movable plate extending from the fixing plate, it could increase the power and shading area to supply more waiting passengers to enjoy the cool at summer noon, and when they don't need the shade, the movable plate could retract and overlap with the fixed plate.

The using of new energy bus station also includes temperature sensing device. The actuation system in 
accordance with the temperature sensing device of induction to control board extending or overlapping activities results to make: when the air temperature rises, the actuation system drives the movable plate to increase the shielding area out of the ceiling; when the air temperature reduces, the actuation system drives the movable plate back shrinkage and fixed plate overlap on the shielding area reduced ceiling. So, it could extend or retract the movable plate automatically according to the temperature of the air. In the sense that the movable plate and the fixed plate is necessary, because the moving plate and the fixed plate overlay, the shadow area is smaller, thereby to reduce the bus near the station 200 distance. Therefore, only under high temperature, the embedded movable solar panels could extend, which means at this time the advantages of movable plate are more prominent compared to that of overlapping, and it is also the main innovation of this design.

\section{B. The transformation of station space:}

Space station expansion design of bus station to remove billboards between previous two pillars, increasing passengers' waiting space. It could provide real-time traffic data for image display on both sides of the pillars, and set moving light wind prevention barrier around the station, and according to the need of passengers to give free opening and closing to alleviate the problem of waiting space in cold winter.

\section{Air conditioning system:}

Adding cooling appliances in station is in accordance with the needs and the PV power to air conditioning or fan. In a large station, because the PV power is relatively large, we can install air conditioning; in a small and medium-sized airconditioning platform, the power is small, we can install electric fan.

\section{Improvement of humanized function:}

Adding the humanized function to set in the waiting room short-term emergency charging facilities for those who need to charge a mobile phone and other equipment, in addition to provide wireless network, drinking water and other convenient facilities for passengers use.

\section{E. The design of station styling:}

Building materials to improve the design of the station is insulation materials, while the appearance is more modern design to improve the city's portal image.

\section{F. Easily spliced structure:}

Simple structure and easy mass production. The roof and enclosure structure design of bus platform is simple, easy assembly and easy mass production. In the construction of large platform, the direct use of components assembled could reduce on-site construction time.

\section{G. The use of specific instructions:}

- About the intelligent transportation system on public facilities design, the key part of the active plate relates in involving bus station to bus station under the driving system can be induced with the fixed plate stacked or extend the fixed plate to change the shading area of the roof. Through temperature sensing device, the actuation system according to the temperature sensing device to control the induction results out or to make the movable plate overlap: when air temperature rises, the actuation system drives the movable plate to increase the shielding area out of the ceiling; when air temperature reduces, the actuation system drives the movable plate and the fixed plate retraction overlap to reduce the ceiling covered area. The actuation system includes the electric motor arranged on the fixed plate and the connected with battery, output shaft and the motor are connected through a screw and plate fixed on the movable plate on the nut block; the screw penetrated through the nut block, and through the rotation of the driving screw the mother block move to drive the movable plate extends out of the fixed plate. Temperature sensing device comprises a travel switch, a temperature sensing tube closed at one end, mercury installed in the temperature sensing tube and Induction piston rod; the motor and the stroke switch are electrically connected with the piston end set the induction of piston rod in the heat pipe, and the other end the stroke switches the vertical displacement of the connecting rod; the mercury according to the temperature change of expansion or contraction in exchange for the trip switch to change the access mode conversion of the motor. The telescopic group increases with the extension of the movable plate and controls the stretching amount of the movable plate. In addition, personalized services bus station the added including public plug directly through the socket is inserted into the USB and the wireless network can be directly connected to the bus station within the range.

- On the improvement of the intelligent transportation system of public transport passenger data sharing, users can directly download on mobile phone through the application click operation to obtain real-time information; they can also direct viewing of the image information and text data real-time scrolling through the LCD display in the station, which is very convenient.

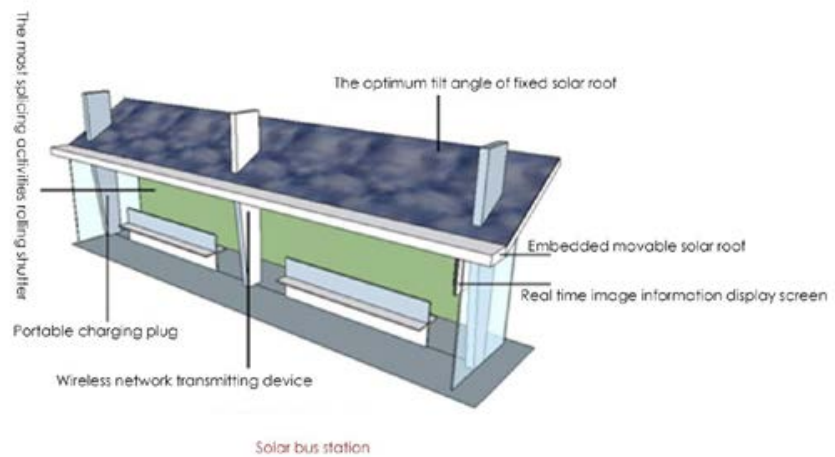

Fig. 1. The intelligent bus station of computer model design

\section{THE IMPROVEMENT OF PUBLIC TRANSPORTATION DATA SHARING}

Use GPS and navigation technology to locate the position of the passengers. They could input the place they want to go to in the real-time image display or on mobile phone APP, then to know the information of the bus and transfer line information 
of nearby subway station, including the waiting time of bus and subway station. The integration and sharing of bus travel information and city fast track traffic information greatly improve the efficiency and convenience of the people's choice of public transportation, arousing the enthusiasm of the people's use of city public transportation, and it is an innovation of this intelligent design.

Buses and the interior of urban rail transit cabinet install the vehicle-mounted camera and computer processing platform, through the face recognition system to count the number of get on and off. Thus we can calculate the number of public transport in use, through computer to process the final feedback to APP or mobile phone display platform. Passengers could easily distinguish the degree of congestion of each bus and rail transportation, flexible change travel routes and avoid unnecessary traffic congestion.

\section{CONCLUSION}

The project combines currently problems of public transportation system in Jinan city and seize opportunities arise in the public transportation development of Jinan city in future several years to innovate and transform of the city traffic system of Jinan City, the main positive significance includes:

Firstly, the project is a humanized design, with the characteristic of convenience, which could meet the growing demand for information. It could provide people with more traffic information, making people's travel more efficient and convenient. In addition, it could also provide some small convenience features, such as wireless networks, emergency mobile phone charging, etc. to further improve the urban infrastructure.

Secondly, this design implements the strategy of sustainable development of the city, through the application of solar technology, conforming the trend of current era - "lowcarbon life, green travel", providing more qualified services and saving more energy. And the convenience stimulates people to use more public transport system instead of the original passive helpless choice, which truly serve the livelihood of people. And because of the long East-West geographical environment, traffic is not convenient, so it's impending to improve public transport system to reduce urban traffic pressure.

Thirdly, the design in accordance with the demand of "wisdom city", using information technology of public transportation network to realize the wisdom operation of public traffic in Jinan city. It has a positive significance on creating a wonderful life for the people in Jinan, to promote the harmonious and sustainable development and the construction of the good image of Jinan City.

\section{REFERENCES}

[1] Li Ming, Research on passenger flow forecast model and selection design of BRT station[J].Beijing Jiaotong University, 2007 (in, Chinese)

[2] Wang Anxu. Research direction of urban bus station in China [J].Jilin College of The Arts, 2009 (in, Chinese)

[3] Jin Rongzhe. Bus station based on human walking space -- Take the bus stop of South Korea Kwangju Wan main road as an example [J].Design art research, 2011 (in Chinese)

[4] Yan Yan. Urban public transport system energy consumption model and calculation method[J].Tsinghua University, 2013 (in Chinese)

[5] He Liming. Microcontroller technology and application[J].Beihang University press[J], 2011 (in Chinese)

[6] Hui Shuangshuang. Wu Yamin.Wang Xiao.Jane Zhu.Chen Xueni.Yuan Fengping. Optimized installation of solar panel[J].School of science, Jiangnan University, 2012 (in Chinese)

[7] Li Qiuqing. Solar energy design and implementation in transportation facilities[J]. Hubei University of Technology, 2011 (in Chinese)

[8] Chen Wei. Optimization design of solar LED street lighting system[J]. Journal of Zhongshan University, 2005 (in Chinese)

[9] HAYJE. Calculation of monthly mean solar radiation for horizontal and inclined surface[J].Solar Energy,1979

[10] Wang Jianyuan. Calculation and distribution of solar radiation in Shandong province[J].Meteorological science and technology, 2006 (in Chinese) 